\title{
Traumatic brain injury among men in an urban homeless shelter: observational study of rates and mechanisms of injury
}

\author{
Jane Topolovec-Vranic PhD, Naomi Ennis BA(Hons), Mackenzie Howatt BSc(Hons), Donna Ouchterlony MD, \\ Alicja Michalak MScP MSN, Cheryl Masanic MD, Angela Colantonio PhD OT Reg (Ont), \\ Stephen W. Hwang MD MPH, Pia Kontos PhD, Vicky Stergiopoulos MD MHSc, Michael D. Cusimano MD PhD
}

\section{Abstract}

Background: Little empiric research has investigated the interrelationship between homelessness and traumatic brain injury. The objectives of this study were to determine the rate, mechanisms and associated outcomes of traumatic brain injury among men in an urban homeless shelter.

Methods: We recruited participants from an urban men's shelter in Toronto, Ontario. Researchers administered the Brain Injury Screening Questionnaire, a semistructured interview screening tool for brain injury. Demographic information and detailed histories of brain injuries were obtained. Participants with positive and negative screening results were compared, and the rates and mechanisms of injury were analyzed by age group.

Results: A total of 111 men (mean age $54.2 \pm$ standard deviation $11.5 \mathrm{yr}$; range $27-81 \mathrm{yr}$ ) participated. Nearly half $(50$ [45\%]) of the respondents had a positive screening result for traumatic brain injury. Of these, $73 \%(35 / 48)$ reported experiencing their first injury before adulthood $(<18 \mathrm{yr})$, and $87 \%(40 / 46)$ reported a first injury before the onset of homelessness. Among those with a positive screening result, $33(66 \%)$ reported sustaining at least one traumatic brain injury by assault, 22 (44\%) by sports or another recreational activity, $21(42 \%)$ by motor vehicle collision and $21(42 \%)$ by a fall. A positive screening result was significantly associated with a lifetime history of arrest or mental illness and a parental history of substance abuse.

Interpretation: Multiple mechanisms contributed to high rates of traumatic brain injury within a sample of homeless men. Assault was the most common mechanism, with sports and recreation, motor vehicle collisions and falls also being reported frequently by the participants. Injury commonly predated the onset of homelessness, with most participants experiencing their first injury in childhood. Additional research is needed to understand the complex interactions among homelessness, traumatic brain injury, mental illness and substance use.

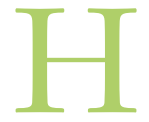
omelessness is an important issue in Canada and is a risk factor for poor health outcomes. In 2011, 1086 shelters with a total of 28495 beds served homeless individuals and families in Canada. ${ }^{1}$ In the same year, an average of 2787 beds were occupied nightly in the shelter system of Toronto, Ontario. ${ }^{2}$ People who are homeless suffer to a greater extent from mental health and substance abuse disorders, are more frequently admitted to hospital (often with prolonged hospital stays) and have a higher mortality rate than low-income individuals in the general population. ${ }^{3-9}$ Although many aspects of homelessness have been studied, there is an emerging interest in exploring traumatic brain injury within this population. Traumatic brain injury, defined as a "blow or jolt to the head or a penetrating head injury that disrupts the function of the brain," ${ }^{10}$ is a leading cause of death and disability. ${ }^{11}$
The severity of traumatic brain injury can range from a brief change in mental status to prolonged coma or death, and the injury itself can result in a wide range of long-term disabilities. Cognitive impairment and mental disorders, common sequelae following traumatic brain injury, ${ }^{12-14}$ are also highly prevalent in homeless populations. ${ }^{15,16}$ Furthermore, cognitive impairment may increase the risk of becoming and remaining homeless. ${ }^{17}$

Competing interests: None declared.

This article has been peer reviewed.

Correspondence to: Jane Topolovec-Vranic, topolovec-vranicj@smh.ca CMAJ Open 2014.DOI:10.9778/cmajo.20130046 
There has been surprisingly little empiric research regarding the interrelationship between homelessness and traumatic brain injury. One systematic review that included the few studies published to date reported lifetime prevalence of traumatic brain injury ranging between $8 \%$ and $53 \%$ in various homeless populations. ${ }^{18}$ Accurate estimates of the lifetime history (prevalence) of traumatic brain injury within the general population are scarce, which makes it difficult to compare rates of injury among homeless people with rates among those in the community. Two community cohort studies suggested prevalence rates of $3.8 \%$ (for experiencing at least 1 admission to hospital for traumatic brain injury by age 35 ; northern Finland birth cohort) ${ }^{19}$ and $31.6 \%$ (for experiencing a traumatic brain injury for which the person received medical care; Christchurch, New Zealand, birth cohort). ${ }^{20}$ Together, these data suggest that rates may be higher among people who are homeless than within the general community. A recent study estimated that homeless men had rates of head injury 14 times higher than rates for the general population of Canada, with a rate 400 times higher among those who were chronically homeless and had drinking problems. ${ }^{21}$ However, different methods and criteria have been used to screen for and quantify rates of traumatic brain injury in both general and homeless populations, and these differences may be factors in the range of rates reported.

The existing literature on the interrelationship between traumatic brain injury and homelessness suggests that in most cases at least 1 injury occurred before the onset of homelessness, ${ }^{22,23}$ and a history of traumatic brain injury has been associated with significantly increased likelihood of seizures, mental health problems, drug problems, poorer physical health status and poorer mental health status. ${ }^{23}$ These findings are generally based on small sample sizes, nonrandomized study designs and basic questioning, with only one study having used a validated screening questionnaire for traumatic brain injury. ${ }^{24}$ Furthermore, no studies have reported in detail the mechanisms of traumatic brain injuries among those who are homeless. We aimed to determine the prevalence of traumatic brain injury in a sample of homeless men, the timing and mechanisms by which the injuries occurred, and whether there were differences in reported rates of arrests, lifetime history of substance abuse, mental illness, seizures and/or parental history of substance abuse between those with and without self-reported traumatic brain injury.

\section{Methods}

\section{Selection of participants}

We conducted an observational study of 3 cohorts of men from a single large, urban men's homeless shelter. The cohorts consisted of men from the shelter's hostel program, its harm reduction program and its long-term care program. The hostel provided short-term emergency shelter to homeless men with no other resources or sources of income. The majority of residents in the harm reduction program had chronic alcohol problems. The long-term care program was open to all men over the age of 65 years, selected men over the age of 50 years and men of any age who received pen- sions or were physically or socially vulnerable, mentally ill or physically disabled.

We recruited participants between Aug. 8, 2011, and May 2,2012 . To reduce the potential for sampling bias, the names of individuals staying in each of the units were randomly selected using a computer-generated random number table. Shelter staff approached potential participants according to the randomization scheme with an invitation to participate in the study. Potential participants were eligible for the study if they were at least 18 years of age and were homeless. According to the existing literature, homelessness was defined as "living at a shelter within the last seven days and not having a home of one's own." ${ }^{23}$ Shelter clients were excluded if they were unable to communicate in English, if they had severe mental illness or aggressive behaviours that might have affected the reliability of screening responses or that posed a safety concern for the research staff (as determined by the shelter staff) or if they were incapable of providing consent to participate (as determined by the shelter staff or their treating physician).

\section{Procedure}

This study was approved by the Research Ethics Board of St. Michael's Hospital, Toronto. After written consent was obtained, research staff conducted face-to-face interviews with each participant. Each participant was given \$20 for participating in the study.

\section{Study instruments}

We obtained self-reported information on participants' demographic characteristics, personal health history (including history of mental illness, seizures and substance abuse), duration of homelessness, parental history of substance abuse, history of arrest and history of injury. These data were documented on a data collection form created for this study and administered by the research staff.

We used the Brain Injury Screening Questionnaire ${ }^{25}$ to determine lifetime incidence of traumatic brain injury. The structure of this questionnaire is based on the HELPS Screening Tool $^{26}$ and incorporates elements of symptom checklists developed by Lehmkuhl. ${ }^{27}$

Part I of the questionnaire consists of specific questions related to blows to the head, incidents of loss of consciousness, and periods of being dazed and confused. These questions allow users to determine whether minimal criteria for a brain injury, as defined by the American Congress of Rehabilitation Medicine, ${ }^{28}$ have been met. Respondents were asked about 19 situations in which they might have experienced a blow to the head and, for each situation, to specify how many times they had lost consciousness or become dazed and confused as a result of such a blow. We determined mechanisms of injury on the basis of these items. The 19 situations were collapsed into the following mechanism-of-injury categories, which were based partly on previous research on the incidence of traumatic brain injury within the general population: ${ }^{29,30}$ motor vehicle collisions, assaults, being struck by or against an object, sports- and recreation-related injuries, falls, fainting, 
drug or alcohol blackouts, biking, being hit as a pedestrian and "other" (e.g., injuries on the playground, falling through ice, being struck by a horse).

Part II of the Brain Injury Screening Questionnaire consists of 100 questions on symptoms and functional outcomes (cognitive, physical, emotional) related to brain injury and documents the occurrence and frequency of these problems on a Likert scale from "never" to "daily or almost daily." Part III of the questionnaire asks about factors other than a brain injury (e.g., medication use, psychiatric illness, fetal alcohol syndrome) that might account for symptoms and impairments.

An individual can receive either a negative screening result or a low-, moderate-, or high-probability positive screening result for traumatic brain injury. Algorithms that take into account numbers of blows to the head, duration of loss of consciousness and periods of being dazed and confused, and number of sensitive and specific symptoms are used to differentiate between screening categories on the Brain Injury Screening Questionnaire. Twenty-five symptom items are considered to be sensitive and specific on the basis of normative data from a sample of 410 individuals with mild and moderate to severe injury. ${ }^{31}$ The Brain Injury Screening Questionnaire has been validated with 75 community-dwelling adults with mild to severe injury ${ }^{32}$ and has been used with children, ${ }^{33}$ individuals accessing substance abuse services ${ }^{34}$ and collegiate athletes. ${ }^{35}$ However, it has yet to be validated in a homeless shelter setting. To be conservative in our estimates, we grouped negative and low-probability screening results from the Brain Injury Screening Questionnaire together and considered this group to represent negative screening results for traumatic brain injury. We grouped moderate- and high-probability screening results from the questionnaire together and considered this group to represent positive screening results for traumatic brain injury.

Although the Brain Injury Screening Questionnaire does not specifically assess severity of injury, we classified severity for participants with a positive screening result on the basis of self-reported longest duration of loss of consciousness after a blow to the head: less than 20 minutes (mild), 20 minutes to 24 hours (moderate) or more than 24 hours (severe). ${ }^{23}$

\section{Statistical analysis}

We used SPSS (version 19.0) to analyze the data, using Mann-Whitney $\mathrm{U}$ tests, $\chi^{2}$ tests and $t$ tests (for normally distributed data) to compare characteristics for participants with positive and negative screening results for traumatic brain injury. As an additional analysis, we analyzed the rates and mechanisms of injury by participants' age, using 3 age groups for comparison with previous reports: less than 40 years, $40-$ 60 years, and 60 years or older. ${ }^{29,30,36}$

\section{Results}

\section{Characteristics of participants}

Of 185 men screened for eligibility, 133 men were approached to participate in the study, and 120 (90\%) of these consented to do so (Figure 1). One of these participants did not com- plete the entire study protocol because of low engagement and difficulty with English words, but some of his data are included in the analysis. Data from 9 participants were excluded post hoc because of concerns on the part of the research team regarding their capacity to consent to the research or provide reliable data (e.g., were clearly intoxicated or delusional during the interview). On average, interviews took 52.7 minutes (standard deviation [SD] $21.3 \mathrm{~min}$ ) to complete, and 36 (32\%) of the participants needed breaks, which lasted 11.8 minutes (SD $13.8 \mathrm{~min}$ ) on average. Six (5\%) of the participants took more than one break.

The final study sample consisted of 111 men (20 from the hostel program, 41 from the harm reduction program and 50 from the long-term care program). Participants from the 3 programs differed significantly in terms of age, history of arrest, lifetime history of substance abuse and lifetime history of seizures (Table 1).

\section{Rates and characteristics of traumatic brain injury}

Nearly half of the participants $(50[45 \%])$ had a positive screening result for traumatic brain injury, according to the Brain Injury Screening Questionnaire, with rates differing significantly among participants in the 3 programs (ranging from $30 \%$ in the long-term care program to $65 \%$ in the hostel program; Table 1). There were no differences in proportions of respondents with positive and negative screening results by age. Participants with a positive screening result for traumatic brain injury were significantly more likely to have been arrested, to have a lifetime history of mental illness and to have parental history of substance abuse (Table 2).

Self-reported mechanisms of injury were determined for those with a positive screening result (Figure 2). If a participant indicated that he had experienced loss of consciousness or was dazed and confused at least once following a blow to the head in a given situation, that situation was counted as a

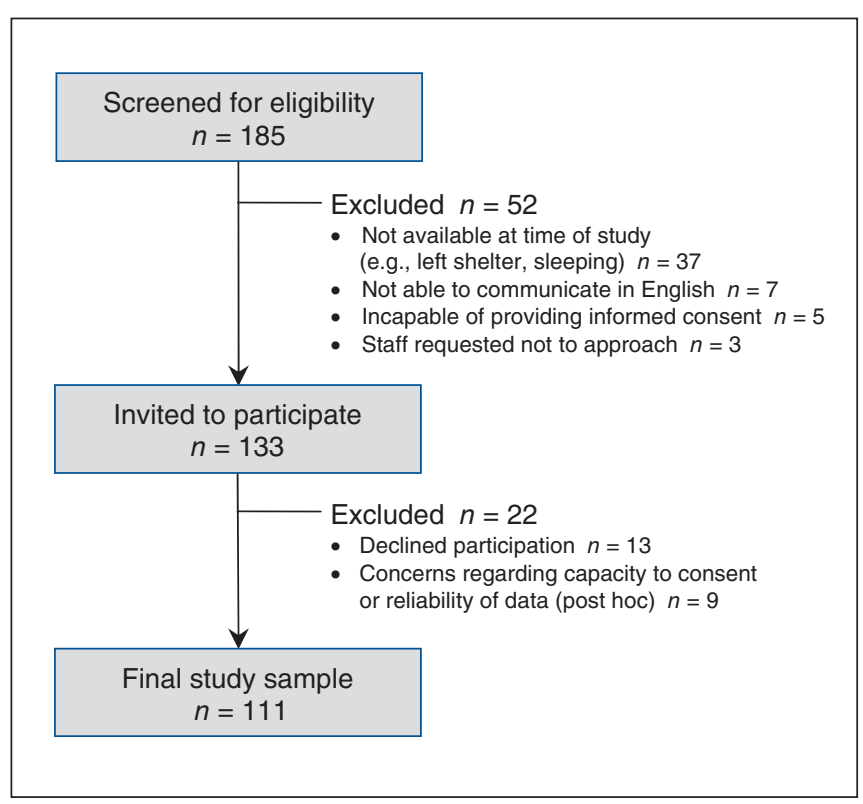

Figure 1: Flow diagram of participant recruitment. 
mechanism of injury. Among the 50 participants with a positive screening result, assaults (including physical abuse and mugging; 33 [66\%]), sports and recreation (22 [44\%]), motor vehicle collisions (21 [42\%]) and falls (21 [42\%]) were the most commonly reported mechanisms. However, the mechanisms of injury varied by age group, with drug or alcohol blackout leading to a fall being the most common mechanism of traumatic brain injury reported by those under 40 years of age, and assault being the most common mechanism reported by those 40 years of age or older (Figure 2).

The temporal relationship between traumatic brain injury and onset of homelessness was available for 46 of the 50 participants with a positive screening result. Among these participants, $40(87 \%)$ reported experiencing at least 1 injury before the onset of homelessness. The median age at first injury for those with a positive screening result was 11.5 years (mean $16.5 \mathrm{yr}, \mathrm{SD} 13.6 \mathrm{yr})$, and 35 (73\%) of the 48 for whom data were available reported experiencing their first injury before adulthood ( $<18 \mathrm{yr})$. These findings indicate that many participants may have experienced their first traumatic brain injury in childhood.

Among those with a positive screening result, 94\% (46/49) reported at least one moderate or severe injury (Table 3 ), and $50 \%(25 / 50)$ reported having had 3 or more blows to the head that resulted in loss of consciousness.

\section{Interpretation}

We used a validated screening tool for traumatic brain injury to determine the rates and mechanisms of injury in 3 groups of men attending an urban homeless shelter. Our findings showed that assault was a leading contributor to traumatic brain injury and that drug or alcohol blackouts were reported by 5 of the 6 participants with a positive screening result who were under 40 years of age. According to data from the Ontario Trauma Registry for 1993-2001, 91\% of people who sustained a traumatic brain injury inflicted by others (i.e., assault) were male, with the highest proportion $(28.0 \%)$ of other-inflicted traumatic brain injuries occurring among those $25-34$ years of age. ${ }^{37}$ Our estimate that $66 \%$ of the participants had sustained traumatic brain injury by assault is much higher than might be expected in the most at-risk age group in the general population.

Rates of other common mechanisms of injury were comparable to those observed in the general population. In Canada, the leading mechanisms of traumatic brain injury leading to hospital admission over the decade 1994-1995 to 2003-2004 were motor-vehicle-related for adults less than 60 years of age and falls for those 60 years of age or older ${ }^{30}$ with assaults reported as the mechanism of injury at a substantially lower rate than we have reported here. Data from Ontario for

Table 1: Characteristics of participants, by shelter program

\begin{tabular}{|c|c|c|c|c|c|}
\hline \multirow[b]{2}{*}{ Characteristic } & \multicolumn{4}{|c|}{ Shelter program; no. (\%) of participants } & \multirow[b]{2}{*}{$p$ value } \\
\hline & $\begin{array}{l}\text { Hostel } \\
n=20\end{array}$ & $\begin{array}{c}\text { Harm } \\
\text { reduction } \\
n=41\end{array}$ & $\begin{array}{c}\text { Long-term } \\
\text { care } \\
n=50\end{array}$ & $\begin{array}{l}\text { Total } \\
n=111\end{array}$ & \\
\hline Age, yr, mean \pm SD & $43.4 \pm 9.4$ & $52.9 \pm 9.3$ & $59.7 \pm 10.7$ & $54.2 \pm 11.5$ & $<0.001$ \\
\hline Ethnic origin, white $(n=110)$ & $11 / 19(58)$ & $35 / 41(85)$ & $38 / 50(76)$ & $84 / 110(76)$ & 0.07 \\
\hline Highest level of education $(n=110)$ & & & & & 0.9 \\
\hline Some high school or less & $10 / 20(50)$ & $17 / 41(41)$ & $21 / 49(43)$ & $48 / 110(44)$ & \\
\hline High school or equivalent & $2 / 20(10)$ & $8 / 41(20)$ & $9 / 49(18)$ & $19 / 110(17)$ & \\
\hline Vocational training, college or above & $8 / 20(40)$ & $16 / 41(39)$ & $19 / 49(39)$ & $43 / 110(39)$ & \\
\hline $\begin{array}{l}\text { Homelessness duration, mo, } \\
\text { median (IQR) }(n=83)\end{array}$ & $\begin{array}{c}24.0 \\
(6.3-60.0)\end{array}$ & $\begin{array}{c}18.5 \\
(10.1-41.5)\end{array}$ & $\begin{array}{c}20.5 \\
(9.0-84.0)\end{array}$ & $\begin{array}{c}20.5 \\
(8.0-72.0)\end{array}$ & 0.9 \\
\hline History of arrest $(n=87)$ & $19 / 20(95)$ & $14 / 18(78)$ & $30 / 49(61)$ & $63 / 87(72)$ & 0.02 \\
\hline $\begin{array}{l}\text { Lifetime history of substance abuse } \\
(n=110)\end{array}$ & $14 / 20(70)$ & $31 / 40(78)$ & $25 / 50(50)$ & $70 / 110(64)$ & 0.02 \\
\hline $\begin{array}{l}\text { Lifetime history of mental illness } \\
(n=103)\end{array}$ & $10 / 19(53)$ & $19 / 35(54)$ & $22 / 49(45)$ & $51 / 103(50)$ & 0.7 \\
\hline Lifetime history of seizures $(n=86)$ & $2 / 20(10)$ & $21 / 31(68)$ & $10 / 35(29)$ & $33 / 86(38)$ & $<0.001$ \\
\hline $\begin{array}{l}\text { Parental history of substance abuse } \\
(n=95)\end{array}$ & $9 / 20(45)$ & $14 / 27(52)$ & $18 / 48(38)$ & $41 / 95(43)$ & 0.5 \\
\hline $\begin{array}{l}\text { Result on screening for traumatic } \\
\text { brain injury* }\end{array}$ & & & & & 0.01 \\
\hline Negative & $7 / 20(35)$ & $19 / 41(46)$ & $35 / 50(70)$ & $61 / 111(55)$ & \\
\hline Positive & $13 / 20(65)$ & $22 / 41(54)$ & $15 / 50(30)$ & $50 / 111(45)$ & \\
\hline
\end{tabular}


almost 55000 emergency department visits and hospital admissions of men with traumatic brain injury indicated that falls, being struck by or against an object, motor vehicle collisions and sport-related injuries were the most common mechanisms, with only $14 \%$ reported as "intentional" injuries. ${ }^{29}$ Importantly, the findings we have reported here reflect lifetime prevalence rates, rather than incidence rates as reported previously in the literature. In addition, our findings were based on self-reported rather than administrative data and thus likely also captured cases of traumatic brain injury that may not have been seen in emergency departments or hospitals. Aside from assaults, the similarity in mechanism of injury between the general and homeless populations is particularly notable, given that, for a majority of homeless individuals, traumatic brain injury has been shown to precede the onset of homelessness and often occurs before adulthood. ${ }^{22,23}$ Further research is needed to validate this hypothesis, as the current study did not specifically examine the mechanisms of participants' first head injuries. However, taken together, these results suggest that traumatic brain injury may be a risk factor for homelessness.

Our finding that mental illness was more prevalent among homeless men with a traumatic brain injury than among homeless men without such injury is concordant with previous research. ${ }^{23}$ Although the temporal relationship between injury and mental illness was not explored in either study, other evidence suggests an increased risk of psychiatric disorders following traumatic brain injury and also suggests that among those with a lifetime history of psychiatric disorders before the injury, the risk for subsequent disorders is increased. ${ }^{38}$ Hwang and colleagues ${ }^{23}$ reported an association between substance abuse (overall rate of $36 \%-49 \%$ ) and seizures (overall rate of $15 \%$ ) and traumatic brain injury. In the current study, rates of both substance abuse and seizures were higher among those with a history of traumatic brain injury, although the differences were not statistically significant. It is possible that the generally high rates of substance abuse and seizures within the current study sample (possibly because participants were recruited at a shelter with an alcohol dependency harm-reduction program, rather than on the streets) made it difficult to detect differences between those with negative versus positive screening results for traumatic brain injury. This possibility was supported by the findings of the 2006/2007 Toronto Street Health survey, a survey of a representative sample of homeless persons in Toronto, ${ }^{39}$ which reported a rate of seizures of $11 \%$ (v. $38 \%$ in our sample). Substance abuse rates were comparable in the Street Health survey and our study (71\% v. 64\%).

Our study showed an association between traumatic brain injury and a history of arrests. Unfortunately, not enough detail

Table 2: Characteristics of participants, by result of screening for traumatic brain injury

\begin{tabular}{|c|c|c|c|c|}
\hline \multirow[b]{2}{*}{ Characteristic } & \multicolumn{3}{|c|}{ Result of screening, no. (\%) of participants } & \multirow[b]{2}{*}{$p$ value } \\
\hline & $\begin{array}{c}\text { Negative } \\
n=61\end{array}$ & $\begin{array}{c}\text { Positive } \\
n=50\end{array}$ & $\begin{array}{c}\text { Total } \\
n=111\end{array}$ & \\
\hline Age, ${ }^{*} \mathrm{yr}$, mean $\pm \mathrm{SD}$ & $55.4 \pm 11.2$ & $52.8 \pm 11.8$ & $54.2 \pm 11.5$ & 0.2 \\
\hline$<40$ & $6 / 61(10)$ & $6 / 50(12)$ & $12 / 111(11)$ & \\
\hline $40-59$ & $30 / 61(49)$ & $26 / 50(52)$ & $56 / 111(50)$ & \\
\hline$\geq 59$ & $25 / 61(41)$ & $18 / 50(36)$ & $43 / 111(39)$ & \\
\hline Ethnic origin $\dagger(n=110)$ & & & & 0.5 \\
\hline White, Caucasian & $45 / 61(74)$ & $39 / 49(80)$ & $84 / 110(76)$ & \\
\hline Black, African, African American & 6/61 (10) & $0 / 49 \quad(0)$ & $6 / 110 \quad(5)$ & \\
\hline Other & $10 / 61(16)$ & $10 / 49(20)$ & 20/110 (18) & \\
\hline Highest level of education $(n=110)$ & & & & 0.4 \\
\hline Some high school or less & $23 / 61(38)$ & $25 / 49(51)$ & $48 / 110(44)$ & \\
\hline High school or equivalent & $12 / 61(20)$ & $7 / 49(14)$ & $19 / 110(17)$ & \\
\hline Vocational training, college or above & $26 / 61(43)$ & $17 / 49(35)$ & 43/110 (39) & \\
\hline Homelessness duration, mo, median (IQR) $(n=83)$ & $18(9.0-60.0)$ & $30(7.3-88.5)$ & $20.5(8.0-72.0)$ & 0.5 \\
\hline History of arrest $(n=87)$ & $33 / 52(63)$ & $30 / 35(86)$ & $63 / 87(72)$ & 0.02 \\
\hline Lifetime history of substance abuse $(n=110)$ & $36 / 60(60)$ & $34 / 50(68)$ & $70 / 110(64)$ & 0.4 \\
\hline Lifetime history of mental illness $(n=103)$ & $23 / 57(40)$ & $28 / 46(61)$ & $51 / 103(50)$ & 0.04 \\
\hline Lifetime history of seizures $(n=86)$ & $14 / 45(31)$ & $19 / 41(46)$ & $33 / 86(38)$ & 0.2 \\
\hline Parental history of substance abuse $(n=95)$ & $19 / 55(35)$ & $22 / 40(55)$ & $41 / 95(43)$ & 0.05 \\
\hline
\end{tabular}


was collected in the interviews to determine the reasons for arrest or the temporal relationship between arrest and the occurrence of traumatic brain injury and/or the onset of homelessness. A recent meta-analysis showed a higher prevalence of traumatic brain injury in incarcerated groups than in the general population. ${ }^{40}$ This finding is not surprising, as traumatic brain injury is associated with development of aggressive behaviours, violence and impulsivity. ${ }^{40}$ It may be equally likely that impulse control disorders and aggression put individuals at increased risk for both arrests and traumatic brain injury.

We found that parental substance abuse was associated with a positive screening result for traumatic brain injury. This finding may be related to prenatal exposure to substances or to physical abuse or neglect in childhood that resulted in early injuries. The relationship between parental substance abuse and traumatic brain injury among homeless men should be further explored.

\section{Strengths and limitations}

A strength of our study lies in our use of a validated screening tool and our exploration of the mechanisms of injury among homeless men. Participants were randomly selected through unbiased sampling, and the response rate among those eligible to participate was high.

The study also had several limitations. The study sample was limited to homeless men residing in a single shelter, which may limit the generalizability of the results. In particular, there may be important differences in prevalence and characteristics of traumatic brain injury among various groups

\begin{tabular}{|lc|}
\hline $\begin{array}{l}\text { Table 3: Severity of injury among } \\
\text { positive screening result for traumatic brain injury* }\end{array}$ \\
\hline Severity of injury & No. (\%) of respondents \\
\hline Mild & $3(6)$ \\
\hline Moderate & $31(63)$ \\
\hline Severe & $15(31)$ \\
\hline *Injury severity could not be determined for one participant. \\
\hline
\end{tabular}

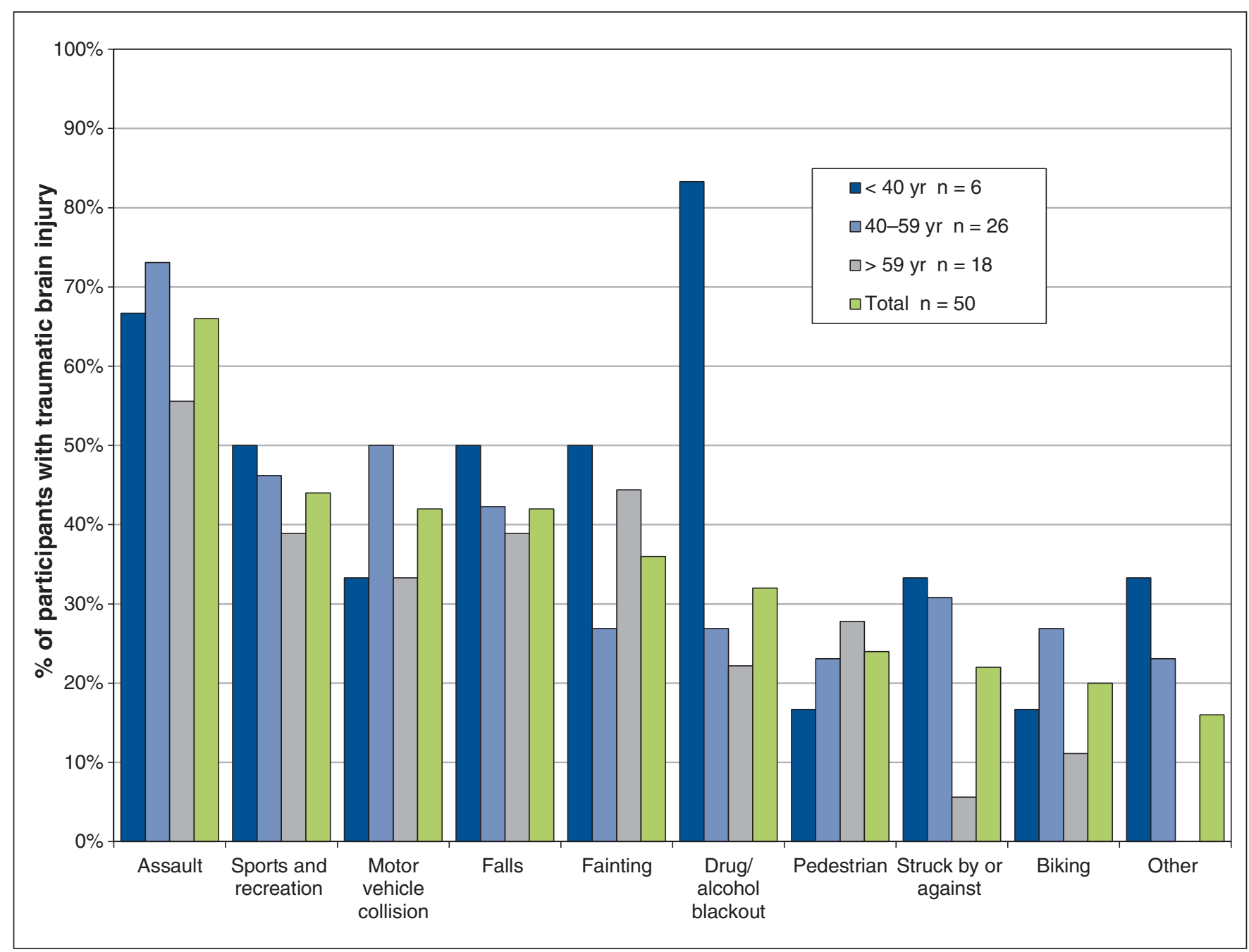

Figure 2: Mechanisms of reported traumatic brain injury by age. Some participants reported sustaining injuries by more than 1 mechanism. In addition, some participants reported multiple injuries by the same mechanism (not illustrated). 
of homeless people (e.g., women, youth, families, those who live on the streets and those who are vulnerably housed).

In choosing the Brain Injury Screening Questionnaire as the screening measure, we opted for a tool that is comprehensive and thorough. We recognize that its validity is still being determined for various populations; however, we selected this questionnaire in the absence of an established gold standard. The literature and evidence for screening tools for traumatic brain injury is an emerging area of research, and other screening tools, such as the Ohio State University screening measure, ${ }^{41}$ the Traumatic Brain Injury Questionnaire ${ }^{42}$ and the Brief Traumatic Brain Injury Screen, ${ }^{43}$ are also available. None of these tools have been validated for use with individuals who are homeless.

The data collected in this study were obtained through selfreporting and may be subject to recall bias. For example, some individuals who sustain a traumatic brain injury will learn of the duration of their loss of consciousness through witness reports or hospital records, but other individuals will estimate the duration of loss of consciousness on their own. Overestimation is likely in such cases, as periods of anterograde and/or retrograde amnesia may accompany such events, which to the individual would feel like loss of consciousness. With self-reporting, there is also the possibility of social desirability bias, which may lead to underreporting of sensitive histories such as those related to personal and/or family substance use or mental health.

In retrospect, we could have extracted more detail to examine the mechanisms of injury. For example, although sportsand recreation-related injuries were common mechanisms of traumatic brain injury in the sample, we did not collect information as to whether participants were intoxicated at the time of injury or if the injury was a result of aggression in sport. Determining at-fault versus victimization mechanisms of injury could have important implications for identifying and treating the emotional sequelae.

\section{Conclusion}

The current findings have important implications for those caring for survivors of traumatic brain injury. Health care providers may wish to consider patients' risk factors for homelessness and how interventions and treatments for traumatic brain injury could target social functioning. Qualitative methods could provide more insight into the experiences and meaning of living with traumatic brain injury for individuals who are homeless. This is an important direction for future inquiry, since previous studies have shown that professionals often lack understanding of the personal and social implications of a traumatic brain injury. ${ }^{44}$

A myriad of factors may lead an individual to homelessness, and brain injury is just one among many complex issues faced by this population. However, the identification of past traumatic brain injury may help to shed light on some of these complex issues. Screening for such injury may provide insight into the cognitive, behavioural and mental health issues that homeless persons face. Additional research on temporal relationships and other factors related to traumatic brain injury and homelessness would be valuable.

\section{References}

1. Homelessness Partnership Secretariat. 2011 shelter capacity report. Ottawa $(\mathrm{ON})$ : Human Resources and Skills Development Canada; 2012.

2. General Manager, Shelter, Support and Housing Administration. 2012 per diem rates for the purchase of service shelter system. Toronto (ON): City of Toronto; 2012.

3. Hwang SW, Wilkins R, Tjepkema M, et al. Mortality among residents of shelters, rooming houses, and hotels in Canada: 11 year follow-up study. BM7 2009; 339:b4036.

4. Frankish CJ, Hwang SW, Quantz D. Homelessness and health in Canada: research lessons and priorities. Can F Public Health 2005;96:S23-9.

5. Hwang SW. Is homelessness hazardous to your health? Obstacles to the demonstration of a causal relationship. Can 7 Public Health 2002;93:407-10.

6. Hwang SW. Mortality among men using homeless shelters in Toronto, Ontario. 7AMA 2000;283:2152-7.

7. Fischer PJ, Breakey WR. The epidemiology of alcohol, drug, and mental disorders among homeless persons. Am Psychol 1991;46:1115-28.

8. Morrison DS. Homelessness as an independent risk factor for mortality: results from a retrospective cohort study. Int 7 Epidemiol 2009;38:877-83.

9. Highley JL. Traumatic brain injury among homeless persons: etiology, prevalence, and severity. Nashville (TN): National Health Care for the Homeless Council, Inc., Health Care for the Homeless Clinicians' Network; 2008.

10. Faul M, Xu L, Wald MM, et al. Traumatic brain injury in the United States: emergency department visits, hospitalizations and deaths 2002-2006. Atlanta (GA): Centers for Disease Control and Prevention, National Center for Injury Prevention and Control; 2010

11. Thurman DJ, Alverson C, Dunn KA, et al. Traumatic brain injury in the United States: a public health perspective. 7 Head Trauma Rehabil 1999;14:602-15.

12. Wei W, Sambamoorthi U, Crystal S, et al. Mental illness, traumatic brain injury, and medicaid expenditures. Arch Phys Med Rebabil 2005;86:905-11.

13. Whelan-Goodinson R, Ponsford J, Johnston L, et al. Psychiatric disorders following traumatic brain injury: their nature and frequency. 7 Head Trauma Rehabil 2009;24:324-32.

14. Bryant RA, O'Donnell ML, Creamer M, et al. The psychiatric sequelae of traumatic injury. Am 7 Psychiatry 2010;167:312-20.

15. Martens WH. A review of physical and mental health in homeless persons. Public Health Rev 2001;29:13-33.

16. Burra TA, Stergiopoulos V, Rourke SB. A systematic review of cognitive deficits in homeless adults: implications for service delivery. Can 7 Psychiatry 2009; 54:123-33.

17. Backer TE, Howard EA. Cognitive impairments and the prevention of homelessness: research and practice review. 7 Prim Prev 2007;28:375-88.

18. Topolovec-Vranic J, Ennis N, Colantonio A, et al. Traumatic brain injury among people who are homeless: a systematic review. BMC Public Health 2012; $12: 1059$.

19. Winqvist S, Lehtilahti M, Jokelainen J, et al. Traumatic brain injuries in children and young adults: a birth cohort study from northern Finland. Neuroepidemiology 2007;29:136-42.

20. McKinlay A, Grace RC, Horwood LJ, et al. Prevalence of traumatic brain injury among children, adolescents and young adults: prospective evidence from a birth cohort. Brain Inj 2008;22:175-81.

21. Svoboda T, Ramsay JT. High rates of head injury among homeless and lowincome housed men: a retrospective cohort study. Emerg Med 72013 Apr. 27 [Epub ahead of print].

22. Oddy M, Moir JF, Fortescue D, et al. The prevalence of traumatic brain injury in the homeless community in a UK city. Brain Inj 2012;26:1058-64.

23. Hwang SW, Colantonio A, Chiu S, et al. The effect of traumatic brain injury on the health of homeless people. CMA7 2008;179:779-84.

24. Hux K, Schneider T, Bennett K. Screening for traumatic brain injury. Brain Inj 2009;23:8-14.

25. Gordon WA, Brown M, Hibbard M. Brain Injury Screening Questionnaire (BISQ) guidelines for web-based version. New York (NY): Mount Sinai Medical Center; 2010 .

26. Picard M, Scarisbrick D, Paluck R. H.E.L.P.S.: a brief screening device for traumatic brain injury. New York (NY): Comprehensive Regional Traumatic Brain Injury Rehabilitation Center; 1991.

27. Lehmkul D. The TIRR symptom checklist. Houston (TX): Institute of Rehabilitation Research; 1988.

28. American Congress of Rehabilitation Medicine, Head Injury Interdisciplinary Special Interest Group, Mild Traumatic Brain Injury Committee. Definition of mild traumatic brain injury. 7 Head Trauma Rehabil 1993;8(3):86-7.

29. Colantonio A, Saverino C, Zagorski B, et al. Hospitalizations and emergency department visits for TBI in Ontario. Can 7 Neurol Sci 2010;37:783-90.

30. Head injuries in Canada: a decade of change (1994-1995 to 2003-2004). Ottawa (ON): Canadian Institute for Health Information; 2006.

31. Gordon WA, Haddad L, Brown M, et al. The sensitivity and specificity of selfreported symptoms in individuals with traumatic brain injury. Brain Inj 2000; 14:21-33.

32. Goldin-Lauretta Y, Gordon WA, Matsuzawa Y, et al. Screening for traumatic brain injury: a comparison of two distinct approaches. Arch Phys Med Rebabil 2011;92:1692-3. 
33. Cantor JB, Gordon WA, Ashman TA. Screening for brain injury in schoolchildren. 7 Head Trauma Rehabil 2006;21:423-4.

34. Sacks AL, Fenske CL, Gordon WA, et al. Co-morbidity of substance abuse and traumatic brain injury. 7 Dual Diagn 2009;5:404-17.

35. Nichols AJ, Spielman L, Tsaousides T, et al. Lifetime concussion history and symptom report among collegiate athletes. Arch Phys Med Rehabil 2012;93:E27.

36. Injury fact book 2001-2002. Atlanta (GA): Centers for Disease Control and Prevention, National Center for Injury Prevention and Control; 2002.

37. Kim H, Colantonio A. Intentional traumatic brain injury in Ontario, Canada. 7 Trauma 2008;65:1287-92.

38. Hesdorffer DC, Rauch SL, Tamminga CA. Long-term psychiatric outcomes following traumatic brain injury: a review of the literature. 7 Head Trauma Rebabil 2009;24:452-9.

39. Khandor E, Mason K. The street bealth report 2007. Toronto (ON): Street Health; 2007.

40. Farrer TJ, Hedges DW. Prevalence of traumatic brain injury in incarcerated groups compared to the general population: a meta-analysis. Prog Neuropsychopharmacol Biol Psychiatry 2011;35:390-4.

41. Corrigan JD, Bogner J. Initial reliability and validity of the Ohio State University TBI identification method. 7 Head Trauma Rebabil 2007;22:318-29.

42. Diamond PM, Harzke AJ, Magaletta PR, et al. Screening for traumatic brain injury in an offender sample: a first look at the reliability and validity of the Traumatic Brain Injury Questionnaire. 7 Head Trauma Rehabil 2007;22:330-8.

43. Schwab KA, Ivins B, Cramer G, et al. Screening for traumatic brain injury in troops returning from deployment in Afghanistan and Iraq: initial investigation of the usefulness of a short screening tool for traumatic brain injury. $\mathcal{F}$ Head Trauma Rehabil 2007;22:377-89.

44. Jumisko E, Lexell J, Soderberg S. The meaning of living with traumatic brain injury in people with moderate or severe traumatic brain injury. 7 Neurosci Nurs 2005;37:42-50.

\section{Competing interests: None declared.}

Affiliations: Trauma and Neurosurgery Program (Topolovec-Vranic), Li Ka Shing Knowledge Institute, St. Michael's Hospital; Department of Occupational Science and Occupational Therapy (Topolovec-Vranic, Colantonio), University of Toronto; Head Injury Clinic (Ennis, Howatt, Ouchterlony, Michalak, Masanic), St. Michael's Hospital; Toronto Rehabilitation Institute (Colantonio, Contos, Masanic), University Health Network; Dalla Lana School of Public Health (Colantonio, Contos, Cusimano), University of Toronto; Centre for Research on Inner City Health (Hwang, Stergiopoulos), Li Ka Shing Knowledge Institute, St. Michael's Hospital; Division of General Internal Medicine (Hwang), Department of Medicine, University of Toronto; Department of Psychiatry (Stergiopoulos), University of Toronto; Injury Prevention Research Office (Cusimano), Trauma and Neurosurgery Program, Li Ka Shing Knowledge
Institute, St. Michael's Hospital; Division of Neurosurgery (Cusimano), University of Toronto, Toronto, Ont.

Contributors: All of the authors contributed substantially to the conception, design, execution, writing and revision of the manuscript, and all gave final approval for the submitted manuscript. More specifically, Jane Topolovec-Vranic conceived of and designed the study. She also led and oversaw the collection, analysis and interpretation of the data and drafted and revised the article. She is a coinvestigator on the Canadian Institutes of Health Research grant, a portion of which was used to fund the study. Naomi Ennis collected, entered and analyzed data. She also worked on interpreting the results and drafted and revised the article. Mackenzie Howatt collected, entered and analyzed data. He worked on the first draft of the article and made critical revisions to subsequent drafts. Donna Ouchterlony, Alicja Michalak, Cheryl Masanic, Angela Colantonio, Stephen Hwang, Pia Kontos, Vicky Stergiopoulos and Michael Cusimano were involved in the conception and design of the study. Donna Ouchterlony, Cheryl Masanic, Angela Colantonio, Stephen Hwang, Pia Kontos, Vicky Stergiopoulos and Michael Cusimano assisted in interpreting the results and revised the drafts critically for important intellectual content. Alicja Michalak revised the drafts critically for important intellectual content. Michael D. Cusimano is the principal investigator on the Canadian Institutes of Health Research grant, a portion of which was used to fund the study.

Funding: This study was funded by the St. Michael's Hospital Head Injury Clinic, the Canadian Institutes of Health (CIHR) Research Traumatic Brain Injury and Violence Research Team (TIR-103946) and the Ontario Neurotrauma Foundation. Angela Colantonio was supported through the Saunderson Family Chair in Acquired Brain Injury Research at the Toronto Rehabilitation Institute and a CIHR Chair in Gender Work and Health at the University of Toronto (CGW-126580).

Acknowledgements: The authors wish to thank the staff and management at the participating shelter for their support of the project. The authors would also like to acknowledge Jacquelyn A. Andersen, Connor Avery-Cooper, Brianna Empringham, Nadine Kot, Justin Shamis, Michael Taylor and Farhaad Virjee for their assistance with data collection and entry.

Supplemental information: For reviewer comments and the original submission of this manuscript, please see www.cmajopen.ca/content $/ 2 / 2$ /E69/supp1/DC1 